\title{
Impacts of a non-native gastropod with a limited distribution; less conspicuous invaders matter too
}

\author{
Jason P. Hendrickx ${ }^{1}$, Robert G. Creese ${ }^{2}$, Paul E. Gribben ${ }^{3, *}$ \\ ${ }^{1}$ Plant Functional Biology and Climate Change Cluster, and School of the Environment, University of Technology, Sydney, \\ NSW 2007, Australia \\ ${ }^{2}$ New South Wales Department of Primary Industries, Port Stephens Fisheries Institute, Nelson Bay, NSW 2315, Australia \\ ${ }^{3}$ Centre for Marine BioInnovation, and School of Biological, Earth and Environmental Sciences, \\ University of New South Wales, Sydney, NSW 2052, Australia
}

\begin{abstract}
Most studies focus on fast-spreading invasive species with high impacts, whilst invasive species with restricted distributions tend to be neglected in the ecological literature. The New Zealand gastropod, Zeacumantus subcarinatus, introduced into the Sydney region during the 1920-1930s, typically occurs in rock pools in the mid- to high intertidal. Surveys conducted in 2004 indicated $Z$. subcarinatus had a restricted distribution, but little is known about whether it is spreading, the environmental conditions that may promote or inhibit its spread, or its interactions with native species. Surveys conducted in 2012 and 2015 showed Z. subcarinatus maintained a similar distribution to that described in 2004 . However, rock pools at sites where $Z$. subcarinatus was present or absent differed in key characteristics. Rock pools at sites lacking $Z$. subcarinatus had higher cover of macroalgae, reduced cover of bare substratum and higher densities of native gastropods. At invaded sites, there was a significant negative relationship between $Z$. subcarinatus and native gastropod densities. Experimental manipulation of $Z$. subcarinatus confirmed negative effects on the colonization of rock pools by the native gastropod Bembicium nanum, possibly via competition for resources. Impacts on $B$. nanum were discernable at low and high densities of $Z$. subcarinatus. By contrast, $Z$. subcarinatus responded positively to density manipulations of $B$. nanum - possibly higher densities of $B$. nanum indicate higher resource availability. We have shown that invasive species that have restricted distributions can have significant effects on native fauna and that they potentially deserve more research and management consideration than they currently receive.
\end{abstract}

KEY WORDS: Invasive species - Zeacumantus subcarinatus - Impact · Competition · Densitymediated interactions $\cdot$ Distribution $\cdot$ Environmental characteristics $\cdot$ Gastropod

\section{INTRODUCTION}

Most studies on invasive species focus on fastspreading species with high impacts. Much less is known about invasive species that do not spread rapidly, that do not have broad distributions, or whose impacts (negative or positive effects on abundance, fitness and/or life-history traits) on native biota may be more subtle. Such a research bias may lead to the misleading assumption that invasive species with limited distributions are merely innocuous additions to native communities, possibly resulting in an underestimation of their impacts on native biota or the ecosystems in their introduced ranges. Clearly, the study of invasion ecology and the management of invasive species would benefit from a broader understanding of the processes determining the spread and impacts not just of species of noted concern (e.g. those on the top 100 most invasive species list, Lowe et al. 2000) but also for the vast majority of non-native species that are considered less of a threat to the native species and ecosystems they invade. 
Once introduced into a new community, environmental characteristics (biotic and abiotic) can influence the subsequent spread and ultimately the range of invasive species. For example, disturbed environments often promote the spread of invasive species (Hobbs \& Huenneke 1992, Burke \& Grime 1996, Valentine \& Johnson 2003, Bulleri \& BenedettiCecchi 2008). By contrast, more species-rich, undisturbed environments may more efficiently utilise available resources such as space and food and limit the establishment and spread of invasive species (i.e. species-rich environments may provide biotic resistance to invasion) (Stachowicz et al. 1999, Kennedy et al. 2002). In addition, the availability of suitable habitat can also limit the spread of invasive species (Byers 2002). Thus we may predict that environmental conditions - biotic, abiotic or both-differ at sites that are occupied and unoccupied by invasive species. Although determining the mechanisms underpinning the spread of invasive species can be challenging, quantitative surveys comparing environmental characteristics at sites where invasive species have established compared to those where they are absent can provide valuable insights into the processes that may promote or limit their spread and potential impacts. Such surveys are necessary for developing and testing hypotheses regarding processes that may underpin the success or failure of non-native species.

Once established, invasive species can have broadranging effects on native communities (Mack et al. 2000, Levine et al. 2003, Thomsen et al. 2009, Gribben et al. 2013). Studies often employ invader presence/absence experiments, comparing treatments with no invader with those of high invader density to understand their interactions with native species (e.g. Neira et al. 2006, Wright \& Gribben 2008, Gribben et al. 2009, Byers et al. 2010). Importantly, the impacts of invasive species can change with their density (Thomsen et al. 2011, Gribben et al. 2013) and even low densities of invasive species can affect native species (Bulleri et al. 2010, Elgersma \& Ehrenfeld 2011). However, we still know little about whether the impacts of invasive species are consistent with increases in invader density, and the potential for invasive species to have significant impacts at much lower densities than are commonly manipulated. Multiple density treatments are necessary for not only advancing our understanding of the relationships between native and invasive species, but also for making informed decisions. For example, if the effects of invasive species manifest at low densities, then appropriate management actions may need to occur at lower, not just higher, invader densities.
Invasive marine invertebrates have a diverse range of impacts in their exotic ranges. Invasive crabs and starfish are often voracious predators (Grosholz et al. 2000, Ross et al. 2002, 2004), and invasive habitatforming bivalves and ascidians can enhance biodiversity by providing habitat (Crooks 1998, Castilla et al. 2004) but also outcompete native invertebrates. Although less well documented, exotic marine gastropods also affect native marine biota. The common periwinkle Littorina littorea is one of the most abundant molluscs in its invaded range in the Northwest Atlantic, reaching densities of several hundred individuals per square meter (e.g. Petraitis 1987, Carlson et al. 2006). By 'bulldozing' fine depositional sediments from hard substrata and consuming the shoots of saltmarsh, L. littorea changes communities from those indicative of soft-sediment habitats to those representative of rocky shores (Bertness 1984). In northern California, high conversion efficiency of resources by the invasive mudsnail Batillaria atramentaria leads to competitive exclusion of the native mudsnail Cerithidea californica (Byers 2000), although facilitation of native species by invasive Batillarids (e.g. $B$. atramentaria and $B$. australis) has also been observed (Wonham et al. 2005, Thyrring et al. 2013).

Another intertidal Batillarid, Zeacumantus subcarinatus, has colonised intertidal rocky habitat (in particular rock pools) in Sydney, Australia (Andrews et al. 2010). Native to New Zealand (Morton \& Miller 1968), Z. subcarinatus was introduced into the Sydney Region in the 1920 s or 1930s, probably via transTasman shipping (Powell 1979). Z. subcarinatus has not been recorded as an invader anywhere else in the world. The only formal survey of Z. subcarinatus around the Sydney Metropolitan Region was conducted in 2004 and it was present at 9 out of 32 surveyed sites (Andrews et al. 2010). Comparison of this survey with records held at the Australian Museum suggests that it had disappeared from 8 sites where it had been previously recorded and had established in one previously unrecorded site (Australian Museum Malacological Database; see Andrews et al. 2010 for detailed introduction history; their Fig. 1). Z. subcarinatus was twice as abundant in rock pools containing higher levels of coarse sand and shell material, although few environmental attributes were measured, and the abundance of some littorinids was approx. 3 times lower in rock pools containing Z. subcarinatus compared to rock pools where they were absent (Andrews et al. 2010). However, little is known about whether $Z$. subcarinatus is spreading, the environmental characteristics (abiotic or biotic) that may promote or inhibit its distribution, or how it 
interacts with native biota. These are the key issues addressed in this study.

We used quantitative surveys to investigate the following hypotheses (1) since 2004, Z. subcarinatus has spread within and outside its known distribution, (2) environmental conditions (biotic and abiotic) differ in rock pools at sites where $Z$. subcarinatus is present and absent and (3) there are negative relationships between the density of $Z$. subcarinatus and native gastropods. Finally, manipulative experiments were used to test the hypothesis that interactions between invasive $Z$. subcarinatus and the native gastropod Bembicium nanum are influenced by their densities.

\section{MATERIALS AND METHODS}

\section{Study organisms and sites}

Zeacumantus subcarinatus is a small gastropod with an average spire height of approx.16 mm (Morton \& Miller 1968). Z. subcarinatus is commonly found in tide pools in the mid- to high intertidal zone in both its native and invaded ranges. $Z$. subcarinatus is thought to consume articulated coralline algae, Ulva spp. and other epiphytic algae, and/or be a deposit feeder (Morton \& Miller 1968, Miller \& Batt 1973, McClatchie 1979).

Around the Sydney area, Z. subcarinatus occurs with common native marine gastropods, including the top shells Austrocochlea porcata (Adams, 1851) and Bembicium nanum (Lamarck, 1822) (J. P. Hendrickx pers. obs.). A. porcata (Adams, 1851) (Trochidae) has a solid, heavy shell with variable colouration and reaches an average spire height of approx. $25 \mathrm{~mm}$ (Underwood \& Chapman 1995, Edgar 2000). It is highly abundant in a wide range of habitats from exposed rocky shores to sand, seagrass and mangroves in sheltered estuaries, around the mid-tide to upper intertidal zone (Underwood 1984a,b, Edgar 2000). B. nanum, a common periwinkle on Sydney's rocky shores, is found in high abundance on moderately exposed rocky shores from the mid- to high intertidal (Underwood 1984a,b, Edgar 2000). Both A. porcata and $B$. nanum occur in rock pools (Underwood 1984a,b, Edgar 2000) and are likely competitors of $Z$. subcarinatus for resources such as space and/or food.

All sites sampled were chosen because $Z$. subcarinatus had been recently recorded at these sites (Andrews et al. 2010) and/or had rocky shores with sheltered rock pools in the mid- to high intertidal zone, which qualitatively appeared conducive to $Z$. subcarinatus establishment (Fig. 1).

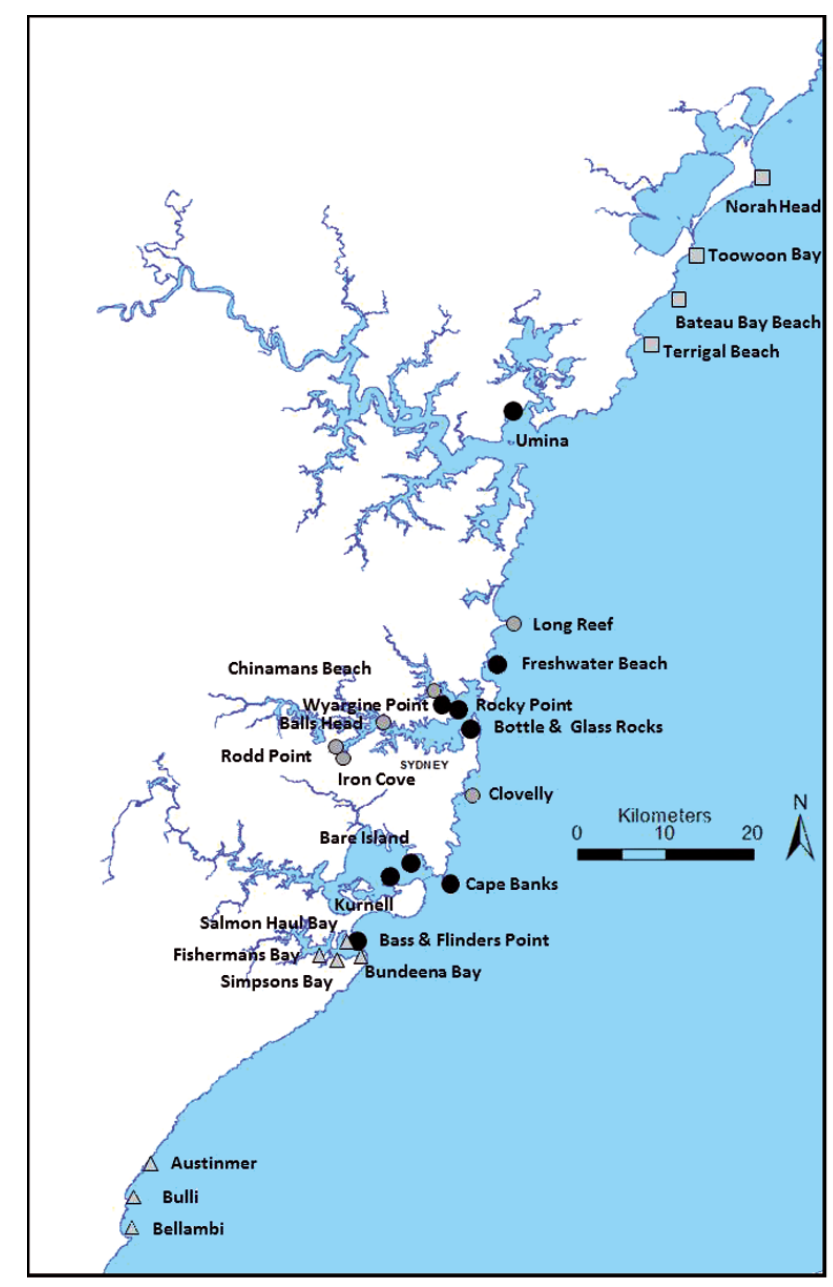

Fig. 1. Sites surveyed around Sydney, Australia, where the invasive gastropod Zeacumantus subcarinatus had previously (black circles; $\mathrm{n}=9$ ) and not previously (grey circles; $\mathrm{n}=6$ ) been recorded within its known distribution, and sites sampled to the north (grey squares; $\mathrm{n}=4$ ) and south (grey triangles; $\mathrm{n}=7$ ) outside its known distribution. Sites within the distribution of $Z$. subcarinatus were previously sampled by Andrews et al. (2010). Sites in our survey were sampled during December 2012 and March 2015

\section{Current distribution of Z. subcarinatus}

In December 2012, to determine whether Z. subcarinatus had spread to new sites within its known range, we resurveyed sites where it had been recorded as present ( $\mathrm{n}=9$ sites) or absent $(\mathrm{n}=6$ sites) in 2004 by Andrews et al. (2010) (Fig. 1, Table 1). We also surveyed coastal sites to the north $(\mathrm{n}=4)$ and south $(\mathrm{n}=4)$ of its previously recorded distribution to determine whether $Z$. subcarinatus had extended its distribution. In addition, during March 2015, we surveyed 4 further sites to more fully explore the distribution and potential spread of $Z$. subcarinatus: 
Table 1. Location of all sites sampled for Zeacumantus subcarinatus during December 2012 and March 2015. Sites include those previously (filled circles) and not previously invaded (open circles) within its known distribution, and sites sampled to the north (squares) and south (triangles) outside its known distribution. Sites within the distribution of $Z$. subcarinatus were previously sampled by Andrews et al. (2010)

\begin{tabular}{|lccc|}
\hline Location & Lat. $\left({ }^{\circ} \mathrm{S}\right)$ & Long. $\left({ }^{\circ} \mathrm{E}\right)$ & Site status \\
\hline Norah Head & 33.1760 & 151.3347 & $\square$ \\
Toowoon Bay & 33.2125 & 151.2935 & $\square$ \\
Bateau Bay & 33.2255 & 151.2906 & $\square$ \\
Terrigal & 33.2653 & 151.2640 & $\square$ \\
Umina & 33.5355 & 151.3140 & $\bullet$ \\
Freshwater Beach & 33.7819 & 151.3024 & $\bullet$ \\
Wyargine Point & 33.8210 & 151.1503 & $\bullet$ \\
Rocky Point & 33.8321 & 151.1508 & $\bullet$ \\
Bottle and Glass Rocks & 33.8490 & 151.2690 & $\bullet$ \\
Cape Banks & 33.9896 & 151.2307 & $\bullet$ \\
Bare Island & 33.9917 & 151.2322 & $\bullet$ \\
Kurnell & 34.0031 & 151.2175 & $\bullet$ \\
Bass and Flinders Point & 34.0760 & 151.1535 & $\bullet$ \\
Long Reef & 33.7430 & 151.3124 & $\bigcirc$ \\
Chinamans Beach & 33.8254 & 151.1418 & $\bigcirc$ \\
Balls Head & 33.8533 & 151.1144 & $\bigcirc$ \\
Iron Cove & -33.8622 & 151.1594 & $\bigcirc$ \\
Rodd Point & 33.8705 & 151.0829 & $\bigcirc$ \\
Clovelly & 33.9152 & 151.2682 & $\bigcirc$ \\
Salmon Haul Bay & 34.0327 & 151.0908 & $\triangle$ \\
Fishermans Bay & 34.0453 & 151.0745 & $\triangle$ \\
Simpsons Bay & 34.0666 & 151.1333 & $\triangle$ \\
Bundeena Bay & 34.0853 & 151.1503 & $\triangle$ \\
Austinmer & 34.3019 & 150.9418 & $\triangle$ \\
Bulli & 34.3392 & 150.9271 & $\triangle$ \\
Bellambi & 34.3682 & 150.9306 & $\triangle$ \\
\hline
\end{tabular}

Umina to the north where $Z$. subcarinatus had previously been recorded as present and 3 previously unsurveyed sites to the south (Austinmer, Bulli and Bellambi) (Fig. 1, Table 1). All sites were exhaustively searched for the presence of $Z$. subcarinatus for $2 \mathrm{~h}$. By starting surveys at low tide, we effectively searched the entire tidal range.

At the same time the surveys were conducted, the density of $Z$. subcarinatus was determined by haphazardly placing a single quadrat $(25 \times 25 \mathrm{~cm})$ in replicate rock pools $\left(\mathrm{n}=10\right.$ rock pools site $^{-1}$ ) and counting the number of $Z$. subcarinatus. All sides of the quadrat were at least $30 \mathrm{~cm}$ from the edge of the rock pool. All rock pools surveyed were in the mid- to high intertidal and had a minimum area of $3 \mathrm{~m}^{2}$. Umina was not included in this survey as it was not sampled in our first survey; it was only surveyed for the presence of $Z$. subcarinatus in our second survey of additional sites.

\section{Differences in rock pool characteristics at sites where $Z$. subcarinatus was present or absent}

In the same quadrates sampled above, to explore the potential mechanisms underpinning the presence or absence of $Z$. subcarinatus at particular sites, we measured a range of biotic (density of native gastropods, \% cover of erect foliose algae and coralline turf) and abiotic variables (rock pool depth, \% cover of bare rock, \% cover of sand and shell hash). Bare rock provides structure and suitable habitat for surface micrograzers (Cacabelos et al. 2010) and encrusting coralline algae may provide further food resources for marine gastropod grazers (Creese 1988). The increasing cover of erect foliose algae and increasing rock pool depth can cause a decrease in grazer abundance (Underwood 1984a,b). All native gastropods in the quadrats were identified and enumerated. Total \% covers of the holdfasts of erect foliose macrophytes attached to the rock surface, coralline algae and bare rock were determined using the point-intersect method (n $=100$ intersecting points within a $25 \times$ $25 \mathrm{~cm}$ quadrat) (Creese \& Kingsford 1988). We only present data on total abundance of native species quadrat $^{-1}$ and not data on individual species as we only found 2 native gastropod species, Bembecium nanum and Austrochlea porcata, of which the former made up $93 \%$ of the abundance of all native gastropods ( $\mathrm{n}=1593$ native gastropods in total) found and the latter the remaining $7 \%$. Depth of rock pools was recorded as the mean of 3 depth measures determined using a ruler haphazardly placed in each rock pool. Only sites within the previous known distribution of $Z$. subcarintus were surveyed $(n=8$ sites where $Z$. subcarinatus was present and $\mathrm{n}=6$ where $Z$. subcarinatus was absent; black and grey circles respectively, Fig. 1). Umina was not included in this survey (as previously described).

A 2-factor nested design was used to investigate differences in rock pool characteristics between sites of different invasion status (fixed factor; 2 levels, $Z$. subcarinatus present or absent) and among sites (random factor nested within invasion status). The analysis was conducted using PERMANOVA (Anderson 2001) with 9999 permutations and Type III sums of squares. We then used principal coordinate analysis (PCO) to investigate relationships between rock pool characteristics and to visualize patterns in the entire set of environmental variables with respect to invasion status. Both analyses were conducted on rank-transformed data and based on Euclidean distances among samples. Linear regression was used to further explore the relationships between individual 
rock pool characteristics and Z. subcarinatus density at invaded sites only.

\section{Density relationships between $Z$. subcarinatus and native gastropods}

Linear regression (SPSS 20.0) was used to investigate the hypothesis that, at sites where $Z$. subcarinatus was present, there was a negative relationship between the density of native gastropods and $Z$. subcarinatus. Using only the data for sites where $Z$. subcarinatus was present, we conducted 2 analyses: the first pooled quadrats across all sites and investigated the influence of $Z$. subcarinatus on native communities at the scale of quadrat; the second investigated whether quadrat scale relationships scaled up to the scale of site and was conducted on the mean values per site by pooling quadrats within sites.

\section{Influence of density on interactions between $Z$. subcarinatus and $B$. nanum}

We conducted 2 experiments to investigate the negative relationships between native gastropods and $Z$. subcarinatus observed in the regression analyses above (see 'Results'). B. nanum was selected as the native competitor as it was the most abundant native gastropod (as described above).

Experiments were conducted simultaneously at Wyargine Point (Fig. 1), a site with high abundance of both $B$. nanum and $Z$. subcarinatus (see 'Results'), allowing for extensive colonization of plots by both species. At this site, 40 plots $\left(n=20\right.$ experiment $^{-1}$; plots $25 \times 25 \mathrm{~cm}$ ) were established in rock pools (1 plot rock pool ${ }^{-1}$; minimum rock pool size $3 \mathrm{~m}^{2}$ ) on the mid- to high rocky intertidal. All sides of the plots were at least $30 \mathrm{~cm}$ from the edge of the rock pool with individual rock pools at least $2 \mathrm{~m}$ apart. Rock pools were devoid of any macroalgae, which avoided the potentially confounding influence of macroalgae in rock pools. Plots were established by placing a quadrat the same size as the plot in the rock pool. Prior to the start of the experiments, and whilst the quadrat was in position, plots were cleared of all other animals and a photo was taken of the quadrat to allow positioning of the quadrat for subsequent sampling. Gastropods used in the experiments were collected from nearby rock pools and kept in separate 201 buckets (one for each species). Gastropods in each bucket were mixed up and randomly assigned to treatments (described below) within $2 \mathrm{~h}$ of collection. Density treatments (described below) for both experiments were randomly allocated to individual plots across all rock pools.

To test the prediction that increasing densities of $Z$. subcarinatus result in lower densities of $B$. nanum, we recorded colonization by $B$. nanum of plots containing 4 different densities of $Z$. subcarinatus $(0,17$, 33 and 50 ind. plot $^{-1}$ ). To test the opposite prediction that increasing densities of $B$. nanum result in lower densities of $Z$. subcarinatus, we conducted the reciprocal experiment by recording colonization of plots by $Z$. subcarinatus containing 4 different densities of B. nanum $\left(0,6,12\right.$ and 18 ind. plot $\left.{ }^{-1}\right)$. For both experiments, density treatments represented $0,33,66$ and $100 \%$ of the maximum observed of that species in any quadrat at any site during the initial sampling.

Sampling was conducted in January 2013, 24, 48, 72 and $96 \mathrm{~h}$ following the establishment of the experiments. $96 \mathrm{~h}$ was chosen as the end point for the experiments as we surmised that this was sufficient time for patterns to emerge. At each visit, we counted the numbers of $B$. nanum and $Z$. subcarinatus in each plot. As the plots were open and the gastropods are mobile, we replaced daily any individuals that had emigrated from the plots to maintain target densities of the species manipulated. Generally, replacement was low and ranged from 2 to $6 Z$. subcarinatus for the first experiment and 1 to $4 \mathrm{~B}$. nanum for the second experiment. Generalized linear models with Poisson distributions were used to determine the effect of $Z$. subcarinatus density (fixed factor) on the colonization of plots by $B$. nanum (Expt 1) and the effect of $B$. nanum on the colonization of plots by $Z$. subcarinatus (Expt 2). In both experiments, because colonization was dependent on interactions between gastropod density and time of sampling (data not shown), we analysed each sampling event separately. Pairwise post hoc tests using least significant difference adjustments for multiple comparisons were used to determine differences among density treatments when significant effects of gastropod density were detected.

\section{RESULTS}

\section{Current distribution of $Z$. subcarinatus}

Overall, Z. subcarinatus had a similar range to that previously described. It was found at 7 of 8 sites where it was previously recorded and was not found at any new sites within or outside its previously reported range. It occurred as far north as Umina but was absent from Bass and Flinders Point, the previ- 


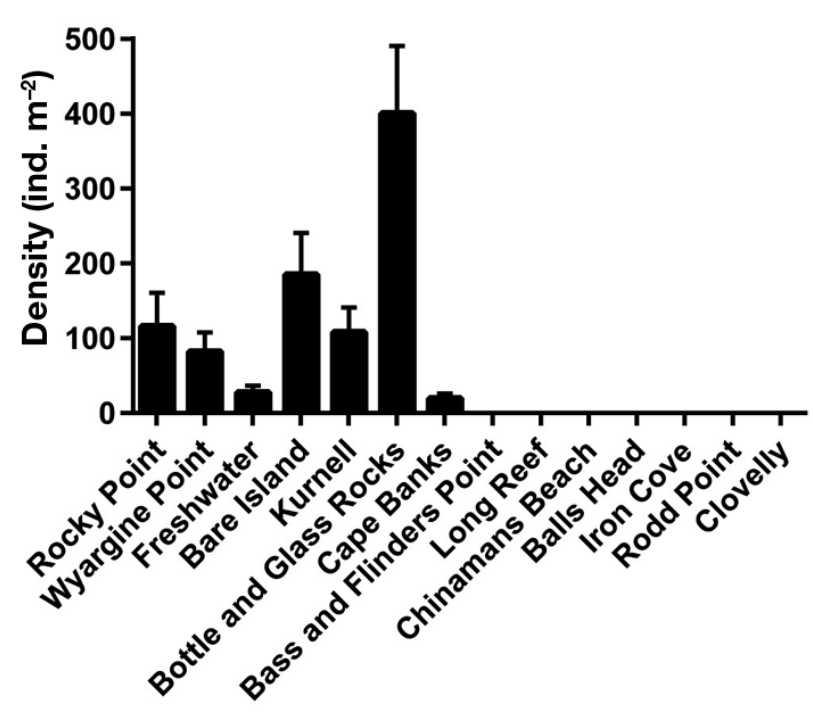

Fig. 2. Mean $( \pm \mathrm{SE})$ density per $\mathrm{m}^{2}$ of Zeacumantus subcarinatus surveyed in rock pool quadrats at 14 sites around Sydney during December 2012. ( $\mathrm{n}=10$ rock pools site ${ }^{-1}$; 1 quadrat rock pool ${ }^{-1}$ )

ously most southern recorded site, despite last being recorded there in autumn 2004 (Andrews et al. 2010). Where it was present, the mean density $( \pm \mathrm{SE})$ of $Z$. subcarinatus ranged from 19.6 (6.8) to 400.8 (109.6) ind. $\mathrm{m}^{-2}$ at Cape Banks and Bottle and Glass Rocks, respectively (Fig. 2).

\section{Differences in rock pool characteristics at sites where $Z$. subcarinatus is present or absent}

Characteristics of rock pools differed between sites within invasion status (pseudo- $F_{12,126}=8.389, \mathrm{p}<$ 0.001 ), but differences between invaded and noninvaded sites were non-significant (pseudo- $F_{1,12}=$ 2.284, $\mathrm{p}=0.053$ ) suggesting that $Z$. subcarinatus was present in rock pools with a broad range of values for the characteristics we measured (Fig. 3). This was supported by the PCO that showed Z. subcarinatus was present at sites widely spread across PCO1 (Fig. 4). However, where it was absent, approximately $75 \%$ of sites were clustered to the left of PCO1 (Fig. 4).

Within rock pools, increasing PCO1 values were positively correlated to the cover of erect foliose algae (Pearson's correlation coefficient $=0.78$ ) and rock pool depth (0.45) and negatively correlated to the density of native gastropods $(-0.76)$ and cover of bare rock (-0.44). Rock pools at sites where $Z$. subcarinatus was absent were thus characterised by a decreasing cover of erect foliose algae, shallower depth, higher densities of native gastropods and increased cover of bare rock. Sites of differing invasion status were evenly spread along PCO2 which was characterised by strong positive correlations with the cover of sand/shell (Pearson's correlation coefficient $=0.78$ ) and depth (0.39). There were negative correlations with cover of bare rock $(-0.73)$ and density of native gastropods $(-0.37)$ with increasing PCO2 values (Fig. 4). Together PCO1 (30.5\%) and PCO2 $(25.3 \%)$ explained $55.8 \%$ of the total variation (Fig. 4).

Interestingly, the linear regression supported the results of the PCO for erect foliose algae as the density of $Z$. subcarinatus positively correlated to the cover of erect foliose algae (Pearson's correlation coefficient $=0.289, \mathrm{p}=0.009$ ). However, at sites where $Z$. subcarinatus was present it was negatively correlated to rock pool depth $(-0.274, \mathrm{p}=0.014)$, the opposite pattern to that observed for sites where it was absent (see PCO results above). This may be explained by the different depth ranges of rock pools in which $Z$. subcarinatus was either present $(0-36 \mathrm{~cm}$ depth) or absent (0-12 cm depth). For example, $Z$. subcarinatus was only absent in shallow pools, but was also found in high densities in shallow pools and density decreased as rock pool depth increased. All other linear regressions were non-significant (all Pearson coefficients $<0.171$, all $\mathrm{p}>0.129$ ).

\section{Density relationships between $Z$. subcarinatus and native gastropods}

The mean density $( \pm \mathrm{SE})$ of native gastropods per $\mathrm{m}^{2}$ at sites sampled within the distribution of Z. subcarinatus ranged from $0.4( \pm 0.4)$ to $222.0( \pm 21.8)$ at Cape Banks and Rodd Point, respectively. For quadrats pooled within sites, there was a strong negative relationship between $Z$. subcarinatus density and native density $\left(\mathrm{R}^{2}=0.542, \mathrm{p}=0.004\right)$. For quadrats pooled across sites, the significant negative relationship persisted but was weaker $\left(R^{2}=0.10, p=\right.$ $0.02)$, highlighting site-to-site variation in the relationship between $Z$. subcarinatus density and native density.

\section{Influence of density on interactions between $Z$. subcarinatus and $B$. nanum}

For the first experiment, in which the density of $Z$. subcarinatus was manipulated, generally, the density of $B$. nanum colonizing plots decreased as the density 

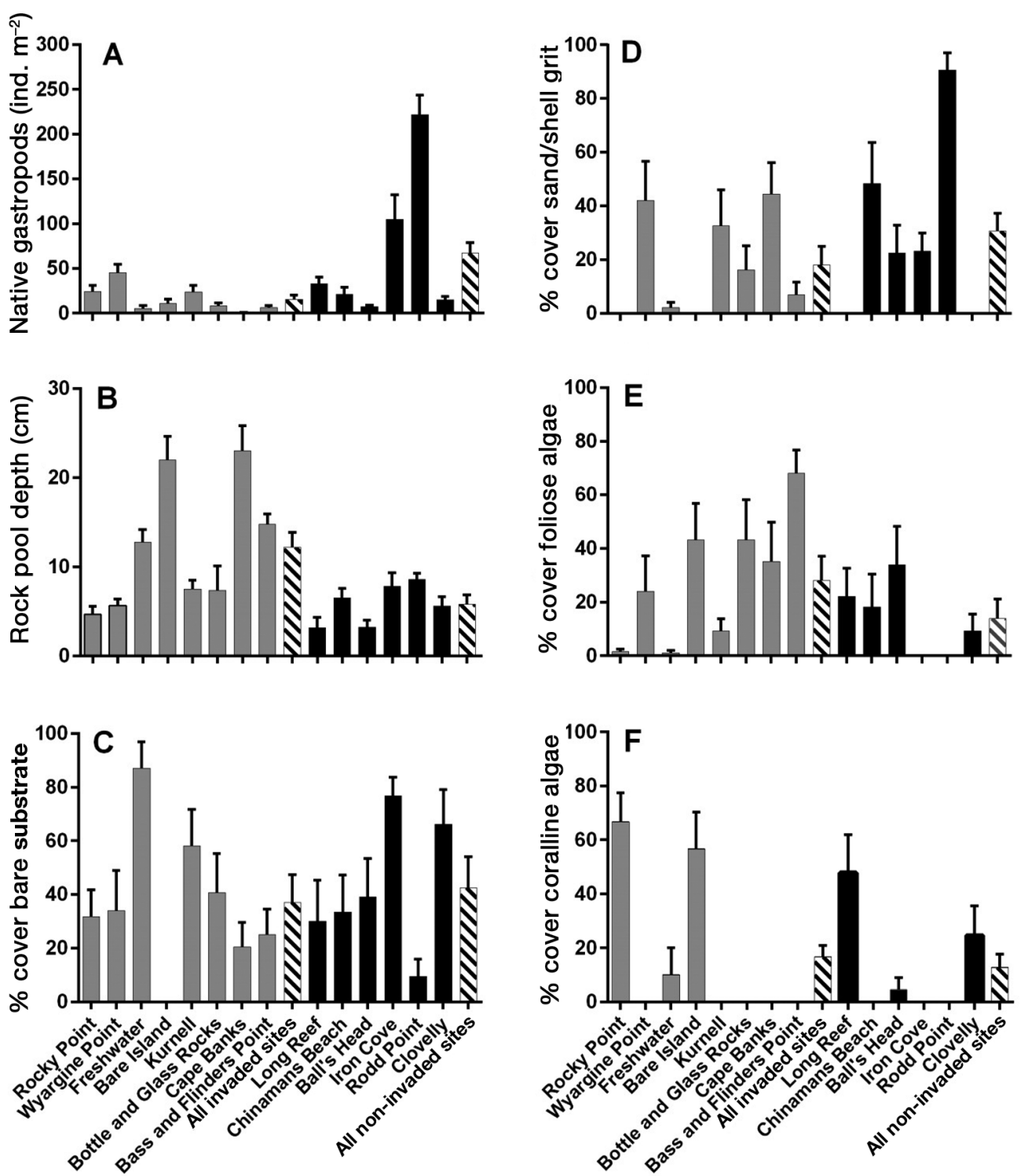

Fig. 3. (A) Density of native gastropods, (B) rock pool depth, (C) \% cover of bare substrate, (D) \% cover of sand/shell grit, (E) $\%$ cover of erect foliose algae and $(\mathrm{F}) \%$ cover of coralline algae in quadrats $(25 \times 25 \mathrm{~cm})$ sampled at sites invaded (n = 8 sites; grey bars) and not invaded ( $\mathrm{n}=6$ sites; black bars) by Zeacumantus subcarinatus. Striped bars on each graph indicate pooled means within invaded and non-invaded sites. Data are mean $\pm \mathrm{SE}$

of Z. subcarinatus increased. However, there was variation in the response of $B$. nanum to the density of $Z$. subcarinatus across sampling times (Fig. 5). Importantly, negative effects of $Z$. subcarinatus on

Fig. 4. Principal coordinate analysis (PCO) on biotic (density of native species, \% cover of erect foliose macrophytes, coralline algae) and abiotic variables (rock pool depth, \% cover of bare substrate) measured in quadrats $(25 \times 25 \mathrm{~cm})$ placed in rock pools ( $\mathrm{n}=1$ quadrat rock pool ${ }^{-1}$ ) at sites where the invasive gastropod Zeacumantus subcarinatus was present ( $\mathrm{n}=7$ sites; grey squares) and absent $(\mathrm{n}=7$ sites; black circles). $\mathrm{n}=10$ rock pools site $\mathrm{s}^{-1}$

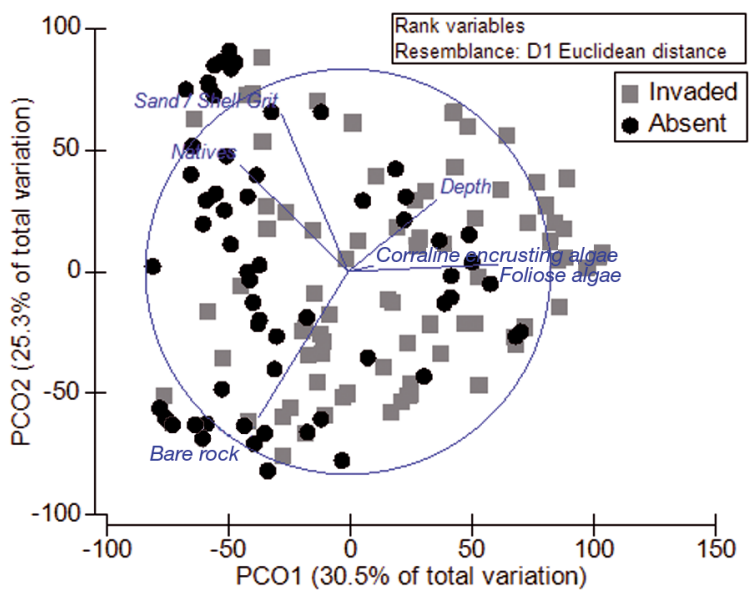



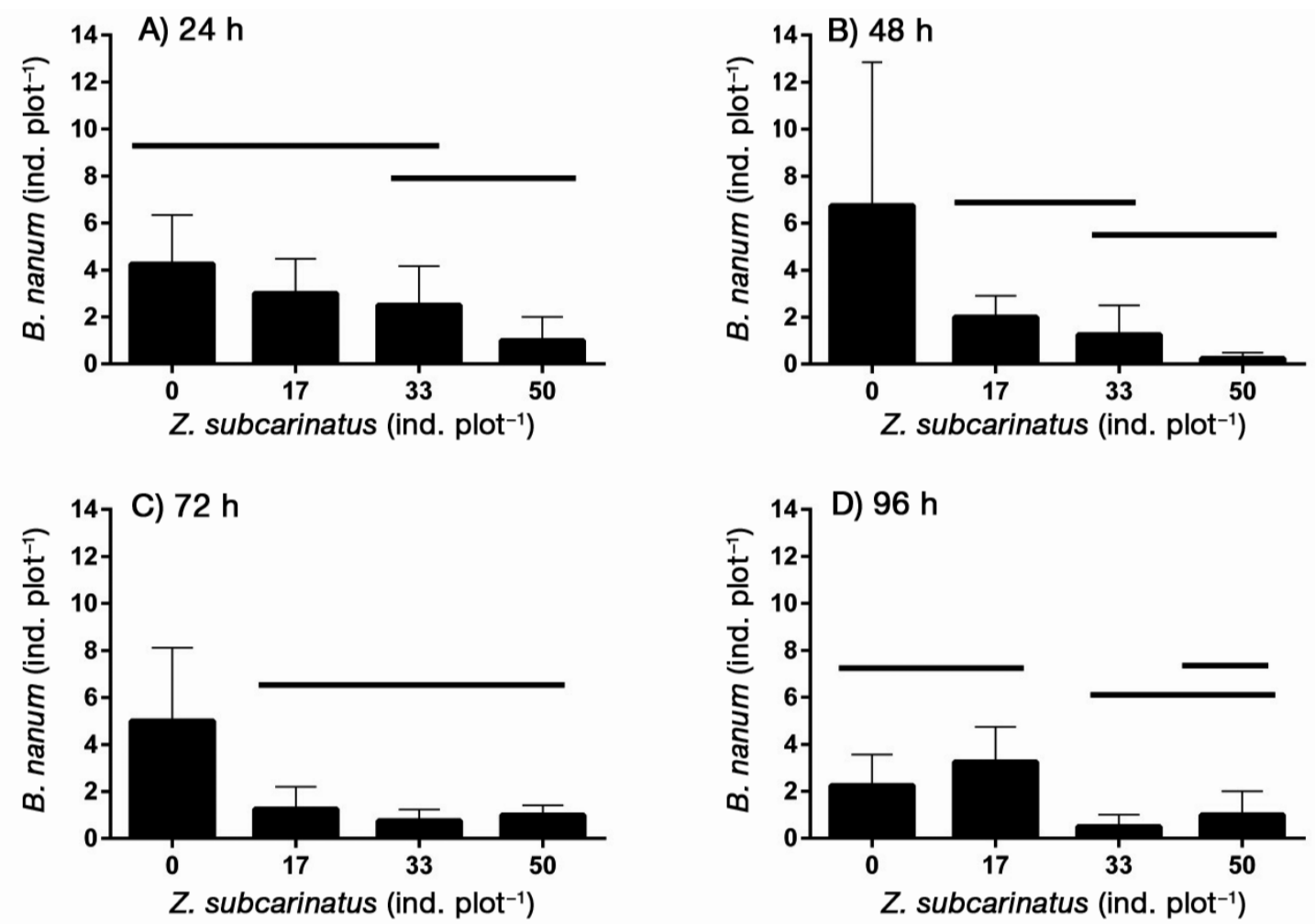

Fig. 5. Mean density $( \pm$ SE) of the native gastropod Bembicium nanum colonising plots $(25 \times 25 \mathrm{~cm})$ after (A) 24 , (B) 48, (C) 72 , (D) $96 \mathrm{~h}$ in rock pools stocked with different densities of Zeacumantus subcarinatus $\left(\mathrm{n}=4\right.$ plots treatment $\left.{ }^{-1}\right)$ at Wyargine Point. Horizontal lines above bars indicate no difference among treatments using least significant difference post-hoc tests

colonisation of plots by B. nanum often occurred at low initial densities $(33 \%$ of the maximum abundance observed in the surveys) of $Z$. subcarinatus (at 48 and 72 h; Figs. 5B,C) and always occurred at densities lower than the highest Z. subcarinatus density manipulated (Fig. 5).

In the second experiment, which manipulated the density of $B$. nanum, and in contrast to the first experiment, the density of $Z$. subcarinatus colonizing plots increased as B. nanum density increased (Fig. 6). Again, there was variation in the response of $Z$. subcarinatus to the density of $B$. nanum across sampling times. Similar to the first experiment, however, positive effects of the density of $B$. nanum on the density of $Z$. subcarinatus often occurred at low B. nanum densities (33\% of the maximum abundance observed in the surveys; Figs. 6B,D).

\section{DISCUSSION}

We found no evidence to support the hypothesis that Zeacumantus subcarinatus has spread since it was last surveyed in 2004. Significantly, however, both correlative data and experiments found negative effects of $Z$. subcarinatus on the density of Bembicium nanum and that these effects manifested at low, and not just high, invader density. In addition, our correlative studies supported the prediction that differences in rock pool characteristics between invaded and non-invaded sites may contribute to colonisation and/or persistence of $Z$. subcarinatus.

Although our search for $Z$. subcarinatus was not exhaustive, it does not appear to have spread since 2004 and thus retains a restricted distribution. In fact, $Z$. subcarinatus, was absent from one site, Bass and Flinders Point, where it was present in 2004 (Andrews et al. 2010). The most likely reason for its lack of spread is that $Z$. subcarinatus larvae, like some other members of the family Batillariidae, are thought to undergo direct development (Adachi \& Wada 1999, Fredensborg et al. 2005), which may limit its dispersal potential. However, veliger larvae with wider dispersal potential have been observed for Batillaria australis (Macintyre 1966). If Z. subcarinatus is a direct developer, then this may be an important mechanism in maintaining a localised distribution in the event that other processes (e.g. 

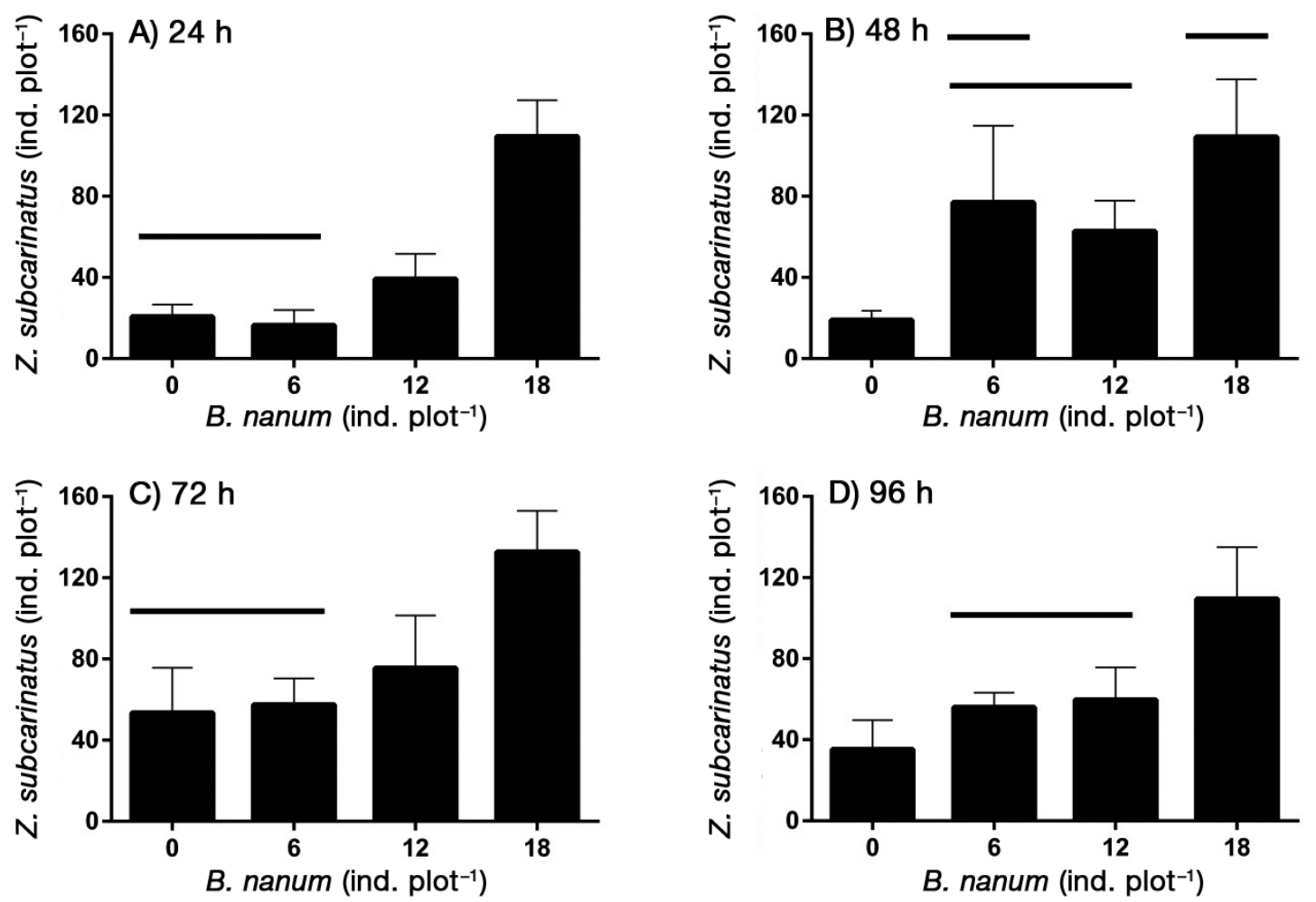

Fig. 6. Mean density $( \pm \mathrm{SE})$ of the invasive gastropod Zeacumantus subcarinatus colonising plots $(25 \times 25 \mathrm{~cm})$ after $(\mathrm{A}) 24$, (B) 48, (C) 72, (D) $96 \mathrm{~h}$ in rock pools stocked with different densities of Bembicium nanum ( $=4$ plots treatment $^{-1}$ ) at Wyargine Point. Horizontal lines above bars indicate no difference among treatments using least significant difference post-hoc tests

hydrodynamics, habitat availability) restrict its expansion.

Comparison of our results with those of Andrews et al. (2010) indicates that, although the distribution of $Z$. subcarinatus has not changed, relative abundances/densities among sites may have. We found the highest densities of $Z$. subcarinatus at Bottle and Glass Rocks, Bare Island and Rocky Point, whereas Andrews et al. (2010) found the highest total population abundances at Kurnell, Wyargine Point, Freshwater and Rocky Point. However, differences between the studies' findings may reflect differences in methodologies. Andrews et al. (2010) determined abundance by counting $Z$. subcarinatus in quadrats and then scaling up by the total area occupied by $Z$. subcarinatus at each site. However, no information on the number of quadrats or area surveyed was given. We suggest that our method is a more rigorous way of estimating the density of $Z$. subcarinatus and other variables and one that can easily be replicated in future surveys.

Where it was present, $Z$. subcarinatus occurred in rock pools that had a broad range of values for those characteristics we measured. However, at sites where the species was absent, rock pools were generally characterised by a higher density of native gastropods, shallower depth, reduced cover of erect foliose algae and more bare rock. Andrews et al. (2010) found similar patterns although they did not measure rock pool depth. Higher densities of native gastropods may provide direct biotic resistance to invasion. However, our experiments showed that, at invaded sites, $Z$. subcarinatus responded positively to density manipulations of $B$. nanum. Instead, both the PCO and the regression analyses suggested positive relationships between macrophyte cover and $Z$. subcarinatus density. Increasing macrophtye cover likely decreases suitable grazing habitat for native gastropods; $B$. nanum and A. porcata apparently prefer to graze on bare substrata (Underwood \& Chapman 1995). Z. subcarintus is smaller than both $B$. nanum and $A$. porcata and it may be better able to exploit the reduced available space and graze on the algae and/or detrital material that may accumulate more readily in rock pools than on open bare substrate. Harder to explain is the relationship between rock pool depth and $Z$. subcarinatus density. The PCO indicated $Z$. subcarinatus was absent from shal- 
low rock pools, but in rock pools where it occurs, the regression analyses indicated a negative relationship between rock pool depth and Z. subcarinatus, i.e. $Z$. subcarinatus abundance decreased with increasing depth. This apparent contradiction may be explained by the different depth ranges of pools in which $Z$. subcarinatus was present or absent. For example, $Z$. subcarinatus was only absent from rock pools with a very narrow depth range (1-12 cm depth). However, Z. subcarinatus was present in rock pools with a very broad depth range (1-36 cm depth) and was found at high densities in shallow pools. The reason why $Z$. subcarinatus is only absent from rock pools with shallow depths while it also occurs in shallow rock pools at higher densities is unknown, but the most parsimonious explanation is that rock pool depth interacts with other rock pool characteristics to determine the presence or absence of $Z$. subcarinatus at shallow rock pool depths. Further experiments are required to tease apart the effects of interactions between biotic (e.g. native gastropod density and algal cover) and abiotic factors (e.g. rock pool characteristics) on the establishment of $Z$. subcarinatus.

Whilst differences in rock pool characteristics among invaded and non-invaded sites likely contribute to the success of Z. subcarinatus, other rock pool characteristics not determined in our study (e.g. rock pool size and total abundance of rock pools) may also contribute to observed patterns of $Z$. subcarinatus abundance. We measured rock pool characteristics in standardised quadrats placed in rock pools $>3 \mathrm{~m}^{2}$ in surface area. Thus we do not know if the relationship between the abundance of $Z$. subcarinatus and rock pool characteristics varies with rock pool size across the full range of possible pool sizes. In addition, the invasibility of a site may also be a function of the total amount of space available for colonisation. Thus future research should also determine how differences in rock pool size and the total number of rock pools influences invasion risk.

In line with studies on rapidly spreading, high profile invasive species with broad ecological impacts, such as the macrophytes Caulerpa racemosa, C. taxifolia and Berberis thunbergii (Bulleri et al. 2010, Elgersma \& Ehrenfeld 2011, Gribben et al. 2013), our quantitative surveys and manipulative experiment clearly showed that even low densities of Z. subcarinatus can have significant effects on the density of $B$. nanum (Fig. 5). This highlights the important role invader density may play in mediating interactions with native species (Thomsen et al. 2011, Gribben et al. 2013), and that thresholds of impacts may occur at lower compared to higher densities. Competition for resources such as food and/or space is a strong structuring force for grazing gastropods (Underwood 1984a, Creese 1988) and invasive gastropods have been shown to outcompete native gastropods for food resources (Byers 2000). Thus competition for resources stands as a reasonable hypothesis to explain the observed effects of $Z$. subcarinatus density on the density of $B$. nanum.

More intriguing was the positive influence of $B$. nanum density on the density of $Z$. subcarinatus (Expt 2). From our experiment it appears that Z. subcarinatus is responding to density cues from native species and not cues (e.g. food) from the plots themselves as we randomly allocated treatments to plots. Although we do not know the mechanisms that may drive this pattern, increasing densities of native species may indirectly indicate higher resource availability (e.g. food resources and/or suitable habitat) for $Z$. subcarinatus. Regardless of the mechanism, the density of $Z$. subcarinatus potentially involves positive and negative feedbacks. At the level of the quadrat (equivalent to an interaction at the scale of $10 \mathrm{~s}$ of $\mathrm{cm}$ ), and in the short term (on the order of days), the density of $B$. nanum positively influences the colonisation of plots by $Z$. subcarinatus, which then negatively feeds back onto the density of $B$. nanum. Teasing apart the mechanisms driving these interactions and the cues from B. nanum that $Z$. subcarinatus is responding to (e.g. water-borne or surface-associated exudates from their mucus or waste products) would be a fruitful area for future research.

We found that the effects of $Z$. subcarinatus on $B$. nanum manifested at low, and not just high, invader densities. This suggests that for both prolific and more subtle invaders, their successful management may need to occur much earlier in the invasion process (i.e. at lower rather than higher densities). In addition, our surveys identified several key differences in rock pool characteristics at sites where $Z$. subcarinatus has invaded compared to those where it is absent. Thus, environmental characteristics may indirectly mediate the impacts on native biota by determining the density of $Z$. subcarinatus. By understanding the rock pool characteristics of sites that could be colonised by $Z$. subcarinatus, we may be able to predict its effects on native biota. However, further experiments are needed to determine the mechanisms that promote or inhibit colonization of sites by $Z$. subcarinatus, and to explain the positive response of $Z$. subcarinatus to the density of $B$. nanum and the negative response of $B$. nanum to $Z$. subcarinatus. 
Acknowledgements. We thank Tim Glasby and 3 anonymous reviewers for helpful comments that improved the manuscript and Antonia Creese for assistance in creating Fig. 1.

\section{LITERATURE CITED}

Adachi N, Wada K (1999) Distribution in relation to life history in the direct developing gastropod Batillaria cumingi on two shores of contrasting substrata. J Molluscan Stud 65:275-287

Anderson MJ (2001) A new method for non-parametric multivariate analysis of variance. Austral Ecol 26:32-46

Andrews V, Middlefart P, Creese RG, Broad A, Davis AR (2010) Distribution and abundance of the introduced gastropod Zeacumantus subcarinatus in the Sydney Region. Molluscan Res 30:131-137

> Bertness MD (1984) Habitat and community modification by an introduced herbivorous snail. Ecology 65:370-381

Bulleri F, Benedetti-Cecchi L (2008) Facilitation of the introduced green alga Caulerpa racemosa by resident algal turfs: experimental evaluation of underlying mechanisms. Mar Ecol Prog Ser 364:77-86

Bulleri F, Balata D, Bertocci I, Tamburello L, BenedettiCecchi L (2010) The seaweed Caulerpa racemosa on Mediterranean rocky reefs: from passenger to driver of ecological change. Ecology 91:2205-2212

> Burke MJW, Grime JP (1996) An experimental study of plant community invasibility. Ecology 77:776-790

Byers JE (2000) Competition between two estuarine snails: Implications for invasions of exotic species. Ecology 81: 1225-1239

> Byers JE (2002) Physical habitat attribute mediates biotic resistance to non-indigenous species invasion. Oecologia 130:146-156

> Byers JE, Wright JT, Gribben PE (2010) Variable direct and indirect effects of a habitat-modifying invasive species on mortality of native fauna. Ecology 91:1787-1798

Cacabelos E, Olabarria C, Incera M, Troncoso JS (2010) Do grazers prefer invasive seaweeds? J Exp Mar Biol Ecol 393:182-187

> Carlson RL, Shulman MJ, Ellis JC (2006) Factors contributing to spatial heterogeneity in the abundance of the common periwinkle Littorina littorea (L.). J Molluscan Stud 72:149-156

> Castilla JC, Lagos NA, Cerda M (2004) Marine ecosystem engineering by the alien ascidian Pyura praeputialis on a mid-intertidal rocky shore. Mar Ecol Prog Ser 268: $119-130$

Creese RG (1988) The ecology of grazing molluscs in northeastern New Zealand and their interactions with benthic algae: a review. NZ J Mar Freshw Res 22:427-444

Creese RG, Kingsford MJ (1988) Organisms of reef and soft strata intertidal environments. In: Kingsford MJ, Battershill CN (eds) Studying temperate marine environments: a handbook for ecologists. Canterbury University Press, Canterbury

Crooks JA (1998) Habitat alteration and community-level effects of an exotic mussel, Musculista senhousia. Mar Ecol Prog Ser 162:137-152

Edgar GJ (2000) Australian marine life: the plants and animals of temperate waters. Reed New Holland, Sydney

Elgersma K, Ehrenfeld J (2011) Linear and non-linear impacts of a non-native plant invasion on soil microbial community structure and function. Biol Inv 13:757-768
Fredensborg BL, Mouritsen KN, Poulin R (2005) Impact of trematodes on host survival and population density in the intertidal gastropod Zeacumantus subcarinatus. Mar Ecol Prog Ser 290:109-117

> Gribben PE, Wright JT, O'Connor WA, Doblin MA, Eyre B, Steinberg PD (2009) Reduced performance of native infauna following recruitment to a habitat-forming invasive marine alga. Oecologia 158:733-745

Gribben PE, Byers JE, Wright JT, Glasby TM (2013) Positive versus negative effects of an invasive ecosystem engineer on different community components. Oikos 122: 816-824

Grosholz ED, Ruiz GM, Dean CA, Shirley KA, Maron JL, Connors PG (2000) The impacts of a nonindigenous marine predator in a California bay. Ecology 81: 1206-1224

> Hobbs RJ, Huenneke LF (1992) Disturbance, diversity, and invasion: implications for conservation. Conserv Biol 6: 324-337

Kennedy TA, Naeem S, Howe KM, Knops JMH, Tilman D, Reich P (2002) Biodiversity as a barrier to ecological invasion. Nature 417:636-638

> Levine JM, Vila M, D'Antonio CM, Dukes JS, Grigulis K, Lavorel S (2003) Mechanisms underlying the impacts of exotic plant invasions. Proc R Soc Lond B 270:775-781

Lowe S, Browne M, Boudjelas S, De Poorter M (2000) 100 of the world's worst invasive alien species: a selection from the global invasive species database. The IUCN Invasive Species Specialist Group (ISSG). www.issg.org

Macintyre RJ (1966) Larval development of Velacumantus australis. Proc Linn Soc N S W 86:183-184

> Mack RN, Simberloff D, Lonsdale WM, Evans H, Clout M, Bazzaz FA (2000) Biotic invasions: causes, epidemiology, global consequences, and control. Ecol Appl 10:689-710

McClatchie S (1979) Grazing of Zeacumantus subcarinatus on Ulva lactuca. Mauri Ora 7:39-45

Miller M, Batt G (1973) Reef and beach life of New Zealand. Collins, Auckland

Morton JE, Miller MC (1968) The New Zealand sea shore. Collins, Auckland

> Neira C, Grosholz ED, Levin LA, Blake R (2006) Mechanisms generating modification of benthos following tidal flat invasion by a Spartina hybrid. Ecol Appl 16: 1391-1404

> Petraitis PS (1987) Factors organizing rocky intertidal communities of New England: herbivory and predation in sheltered bays. J Exp Mar Biol Ecol 109:117-136

Powell AHB (1979) New Zealand Mollusca: marine, land and freshwater snails. Collins, Auckland

Ross DJ, Johnson CR, Hewitt CL (2002) Impact of introduced seastars Asterias amurensis on survivorship of juvenile commercial bivalves Fulvia tenuicostata. Mar Ecol Prog Ser 241:99-112

Ross DJ, Johnson CR, Hewitt CL, Riuz GM (2004) Interaction and impacts of two introduced species on a soft-sediment marine assemblage in SE Tasmania. Mar Biol 144: 747-756

Stachowicz JJ, Whitlatch RB, Osman RW (1999) Species diversity and invasion resistance in a marine ecosystem. Science 286:1577-1579

Thomsen MS, Wernberg T, Tuya F, Silliman BR (2009) Evidence for impacts of nonindigenous macroalgae: a meta-analysis of experimental field studies. J Phycol 45: 812-819

Thomsen MS, Olden JD, Wernberg T, Griffin JN, Silliman 
BR (2011) A broad framework to organize and compare ecological invasion impacts. Environ Res 111:899-908

Thyrring J, Thomsen MS, Wernberg T (2013) Large-scale facilitation of a sessile community by an invasive habitatforming snail. Helgol Mar Res 67:789-794

Underwood AJ (1984a) Microalgal food and the growth of the intertidal gastropods Nerita atramentosa Reeve and Bembicium nanum (Lamarck) at four heights on a shore. J Exp Mar Biol Ecol 79:277-291

Underwood AJ (1984b) Vertical and seasonal patterns in competition for microalgae between intertidal gastropods. Oecologia 64:211-222

Underwood AJ, Chapman MG (1995) Rocky shores. In:

Editorial responsibility: Richard Osman,

Edgewater, Maryland, USA
Underwood AJ, Chapman MG (eds) Coastal marine ecology of temperate Australia. University of New South Wales Press, Sydney

Valentine JP, Johnson CR (2003) Establishment of the introduced kelp Undaria pinnatifida in Tasmania depends on disturbance to native algal assemblages. J Exp Mar Biol Ecol 295:63-90

> Wonham MJ, O'Connor M, Harley CDG (2005) Positive effects of a dominant invader on introduced and native mudflat species. Mar Ecol Prog Ser 289:109-116

Wright JT, Gribben PE (2008) Predicting the impact of an invasive seaweed on the fitness of native fauna. J Appl Ecol 45:1540-1549

Submitted: December 1, 2014; Accepted: August 20, 2015

Proofs received from author(s): September 28, 2015 